\title{
A TRAJETÓRIA DO CLUBE DO CHORO DE BRASÍLIA
}

\author{
Erika Ruas Pereira \\ Maria Tereza Negrão \\ Orientadora
}

Monografia apresentada ao Centro de Excelência em Turismo da Universidade de Brasília como requisito parcial para a obtenção do título de Pós-Graduação Lato Sensu do Curso de Especialização para Professores e Pesquisadores em Turismo e Hospitalidade.

Brasília, DF, Janeiro de 2004 


$$
\begin{gathered}
\text { UNIVERSIDADE DE BRASÍLIA } \\
\text { Centro de Excelência em Turismo } \\
\text { Curso de Especialização para Professores e Pesquisadores em Turismo } \\
\text { e Hospitalidade }
\end{gathered}
$$

\title{
A TRAJETÓRIA DO CLUBE DO CHORO DE BRASÍLIA
}

\author{
Erika Ruas Pereira \\ Maria Tereza Negrão, Dra em Ciências da Comunicação \\ Orientadora
}

$\overline{\text { Membro da Banca Examinadora }}$

Brasília, DF, Janeiro 2004 
Pereira, Erika Ruas

A Trajetória do Clube do Choro de Brasílial Erika Ruas

Pereira.- Brasília UnB/CET, 2004. ix,42p.

Monografia - (Especialização em Turismo e Hospitalidade) Universidade de Brasília, Centro de Excelência em Turismo.

The history of Clube do Choro de Brasilia.

Orientadora: Maria Tereza Negrão

1. Turismo 2. Brasília 3. Música 4.Choro 
ERIKA RUAS PEREIRA

\section{A TRAJETÓRIA DO CLUBE DO CHORO DE BRASÍLIA}

Comissão Avaliadora

Maria Tereza Negrão

Professora Orientadora

Professor(a)

Professor (a)

Brasília, DF, Janeiro, 2004 
Dedico este trabalho aos meus pais: Beijamin e Maria Helena, aos meus irmãos: Karina e Guilherme e à minha segunda família aqui em Brasília: José Couto, Marilda e Renata. 
Agradeço aos meus pais, à minha orientadora Tereza Negrão, aos grandes amigos que fiz no Centro de Excelência em Turismo e ao Juju pelo companheirismo, paciência e dedicação. 
A música é conhecimento, é sentimento e criadora de grandes sonhos.

(Autor Desconhecido) 


\section{RESUMO}

Brasília, cidade planejada, arquitetura arrojada, capital da República e do Poder. População heterogênea, onde sua principal característica é a multiculturalidade.

Hoje, Brasília, representa um dos mais importantes pólos turísticos emergentes do Brasil. É também a capital do rock nacional, exportadora de grandes talentos e difusora do chorinho, gênero musical que atrai um grande público expressivo às dependências do Clube do Choro de Brasília, espaço cultural, onde se pode apreciar música de qualidade através de renomados artistas.

O Clube do Choro não é apenas um espaço cultural, é também um atrativo turístico da cidade, um lugar de entretenimento, mais uma opção cultural para o turista que aprecia a boa música.

Palavras-chaves: Brasília; Turismo; Música; Clube do Choro de Brasília. 


\begin{abstract}
Brasilia, a planned city with fancy architecture and heterogeneous population, capital of the Republic and power which has as its main feature its cultural diversity.

Nowadays, Brasilia represents one of the most important emerging tourism spots in Brazil. It is also the capital of national rock, exporter of talents and diffuser of chorinho, a musical style that attracts a great public to the facilities of Clube do Choro de Brasilia, a cultural place where one can appreciate quality music through wellknown artists.

Clube do Choro is not only a cultural place, but also a tourist attraction to the city, an entertaining place, another cultural option for the tourist who appreciates good music.
\end{abstract}

Key words: Brasilia: Tourism: Music: Clube do Choro de Brasilia. 


\section{SUMÁRIO}

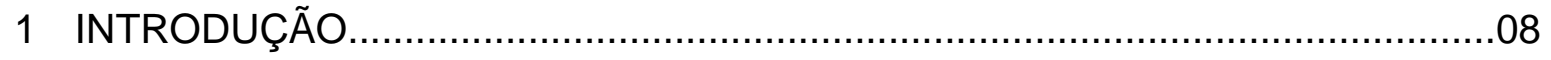

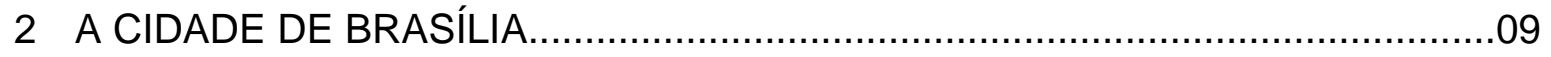

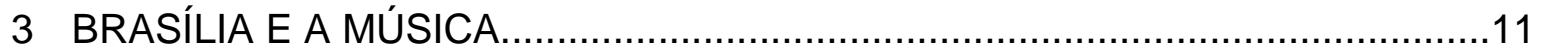

3.1 A Escola de Música de Brasília.................................................................11

3.2 A Universidade de Brasília e o Departamento de Música...................................12

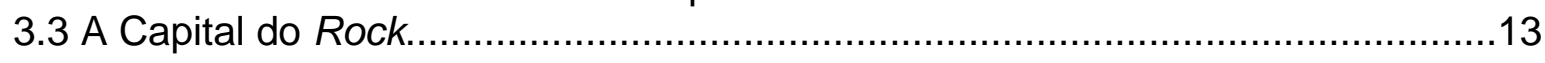

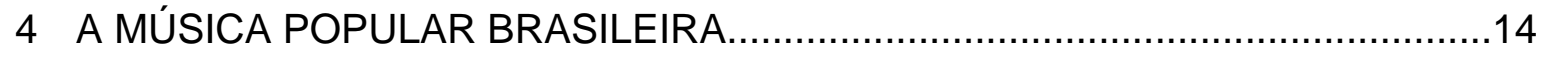

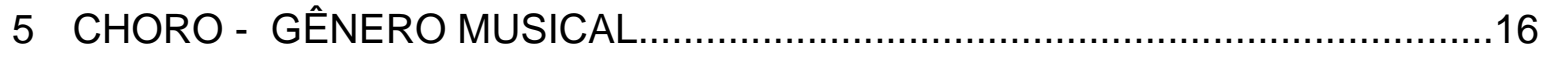

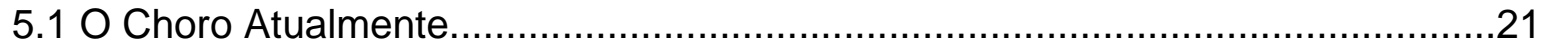

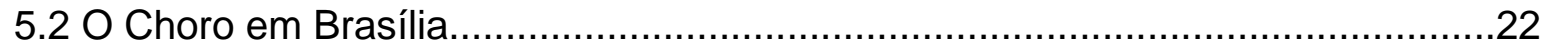

6 A TRAJETÓRIA DO CLUBE DO CHORO DE BRASÍLIA …............................24

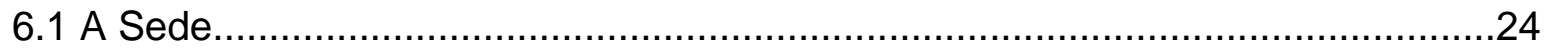

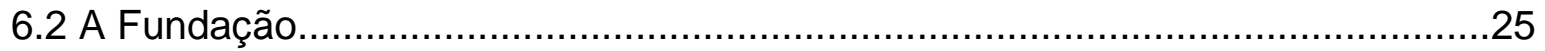

6.3 A Reforma.

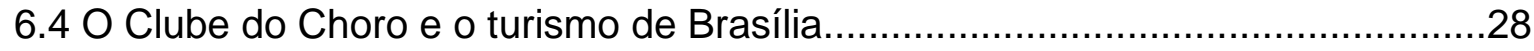

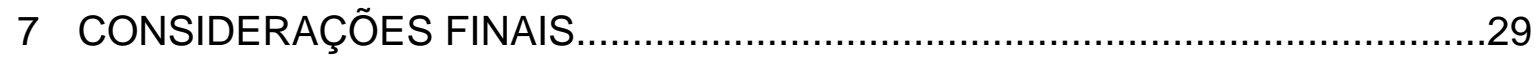

ANEXOS

REFERÊNCIAS BIBLIOGRÁFICAS 


\section{INTRODUÇÃO}

O motivo para a realização desta monografia, partiu do interesse pessoal em divulgar e contribuir para desenvolvimento da atividade turística da capital e sobretudo do Clube do Choro de Brasília.

Nos últimos anos, o turismo no Brasil tem se tornado um segmento relevante na economia, pois é a que mais se expande de forma extremamente veloz. O Brasil tem demonstrado que essa atividade é promissora, podendo ser uma estratégia no combate ao desemprego. No desenvolvimento sócio econômico é instrumento maior para a redução de desigualdades sociais, sendo um excelente gerador de emprego e renda além de valorizar a cultura local.

O objeto de pesquisa desta monografia é o Clube do Choro de Brasília, onde se pretendeu analisar este espaço cultural como um atrativo turístico da cidade de Brasília.

Foram aplicados questionários no espaço do Clube do Choro de Brasília com o intuito de saber o perfil dos freqüentadores bem como se o mesmo é um atrativo turístico da cidade. 


\title{
2. A CIDADE DE BRASÍLIA
}

\author{
Brasília há de constituir um marco milionário na \\ história já gloriosa das terras de Santa Cruz, \\ abrindo novos horizontes de amor, esperança e de \\ progresso entre suas gentes que, únicas na \\ mesma fé, tornar-se-ão aptas aos maiores \\ cometimentos. \\ (Papa João Paulo XXIII)
}

A construção da nova capital, Brasília, iniciou-se em 1956, sendo inaugurada em 21 de abril de 1960 pelo então Presidente da República Jucelino Kubitschek. Seu projeto foi desenhado por Lúcio Costa, e os edifícios principais por Oscar Niemeyer.

\begin{abstract}
Como nasceu Brasília? A respostas é simples. Como todas as grandes cidades, surgiu quase do nada. A idéia da interiorização da capital do país era antiga, remontando à época da Inconfidência Mineira. A partir daí, viera rolando através das diferentes fases da nossa história: o fim da era colonial, os dois reinados e os sessenta anos de República, até 1955. Pregada por alguns idealistas, chegou mesmo, a despeito dessa prolongada hibernação, nunca aparecerá alguém suficientemente audaz para dar-Ihe vida e convertê-la em realidade". (Kubitschek, 1975, pág. 07)
\end{abstract}

Brasília não é apenas resultado do sonho e do planejamento de figuras como J.K, Oscar Niemeyer ou Lúcio Costa. Ela é antes de mais nada a concretização dos sonhos e até mesmo das profecias de diversas pessoas, que mesmo possuindo o sonho de vê-la construída não conseguiram realizá-lo:

Entre os paralelos 15 e 20 graus, havia um leito muito largo. Então uma voz disse repetidamente: "Quando escavarem as minas escondidas no meio destes montes, aparecerá aqui a Grande Civilização, a Terra Prometida, onde correrá leite e mel. Será uma riqueza inconcebível. E essas coisas acontecerão na terceira geração. (São João Bosco)

Em apenas três anos de construção, a cidade combina sua arrojada arquitetura à qualidade de vida, natureza, misticismo, cultura, e claro, à política para nos trazer uma das mais ricas e interessantes histórias do Brasil. 
Planejada para uma população de apenas 500.000 habitantes, Brasília viu sua população crescer muito além do esperado. A parte correspondente ao plano original tornou-se o "Plano Piloto", enquanto sucessivas cidades satélites foram sendo criadas ao longo dos anos para acomodar a população extra. A população de Brasília (incluindo as cidades satélites) já é de mais de 2 milhões de habitantes, sendo o Distrito Federal composto por regiões administrativas.

No ano de 1987, a capital foi reconhecida como Patrimônio Histórico e Cultural da Humanidade. Porém, a cidade é muito mais do que um patrimônio histórico ou um marco arquitetônico. É uma cidade viva e única, uma cidade amada pela maioria dos seus habitantes, uma cidade que realmente vale a pena conhecer!

Sua construção atraiu pessoas de todos os estados, reunindo os vários traços da cultura regional. Somou-se a isto o acesso à cultura de outros povos através das representações diplomáticas. Dessa variada gama de influências surge uma identidade em construção cujo traço predominante é a multiculturalidade. Neste ambiente multicultural formou-se a população de Brasília com sensibilidade artística, que produz arte, aprecia arte e exporta arte.

Esta monografia, que tem como objeto o Clube do Choro de Brasília, tem como uma das preocupações destacar o potencial turístico da cidade de Brasília, no recorte do turismo cultural. Na verdade, longe de ser apenas a capital da república e espaço do poder, Brasília oferece também aos seus habitantes e aos que a visitam, um leque de opções das quais este estudo recorta a arte como função no peculiar espaço do Clube do Choro. Antes, porém, tornar-se necessário retomar uma trajetória da cidade nela destacando aspectos que de algum modo concorreram para a criação do nosso Clube do Choro, com as características que ostenta. A estes aspectos dedico o próximo item. 


\section{BRASÍLIA E A MÚSICA}

As diferentes expressões musicais já são uma característica presente da cidade de Brasília, aqui se pode apreciar e aprender qualquer gênero musical do forró ao hip hop das Satélites, a presença dos diferentes traços culturais da população contribui para o desenvolvimento cultural musical.

\subsection{A Escola de Música de Brasília}

A Escola de Música de Brasília tem se revelado um grande celeiro de talentos do país. (Autor desconhecido)

Em 1963, o ensino musical de Brasília ocorria, fundamentalmente, em dois estabelecimentos da Fundação Educacional do Distrito Federal: o CEMEB (Centro de Ensino Médio Elefante Branco), na Asa Sul, e o CEMAB (Centro de Ensino Médio Asa Branca), em Taguatinga.

Do "Coral de Brasília" fizeram parte muitas pessoas que vieram a ocupar lugar de destaque no cenário musical brasileiro, tanto no gênero erudito quanto no popular: Ney Matrogrosso, José Estevão Gonçalves, José Claver Filho, Patrick Soudant, Guilherme Vaz, Carlos Galvão, Laura Conde, Luiz Carlos Czeko, Vanda Oiticica, para citar alguns nomes. 


\section{2- A Universidade de Brasília e o Departamento de Música}

O Festival é muito importante porque estimula a cultura em seu corpo discente. (Timothy Mulholland, vice-reitor da UNB na abertura do Finca).

A Universidade de Brasília, contribui efetivamente para o desenvolvimento da cultura bem como o da música em Brasília e em todo país, formando profissionais qualificado, desenvolvendo pesquisas e proporcionando eventos culturais diversos para a população.

O Departamento de Música da Universidade de Brasília, foi criado em 1963 e teve como um dos seus fundadores o maestro Cláudio Santoro. Sua regulamentação é de 1971 e atua nos campos da educação musical, performance e composição. Apresenta concertos de professores e convidados, audição de alunos, programa de música de câmara e conta com as orquestras Sinfônicas e de Música Popular.

Os músicos universitários provam que têm talento e a UNB é o berço de grande parte deles. O Festival Universitário de Música Candanga Interno da UNB (Finca), divulga os trabalhos artísticos dos seus jovens. A primeira edição, em 1999, contou com 23 concorrentes. No ano de 2003, 43 bandas concorreram por 43 Centros Acadêmicos. 


\subsection{A Capital do Rock}

Vida longa ao rock de Brasília.

(Dinho, vocalista do Capital Inicial/2003)

Os anos 80 foram pródigos para o rock nacional. Especialmente para a cidade de Brasília, que "exportou" para o restante do país diversas bandas de sucesso, como legião Urbana, Capital Inicial, Plebe Rude, Raimundos e outras.

A era dos super festivais também chegou na capital. Iniciada em 1985, com o primeiro Rock in Rio, no Rio de Janeiro, a onda dos eventos grandiosos atingiu Brasília quase 20 anos mais depois, como foi o caso do Brasilian Music Festival, ocorrido no final de setembro de 2003.

O BMF atraiu mais de 60 mil pessoas ao Autódromo Internacional de Brasília, dando espaço para mais de dez bandas iniciantes de Brasília e de Goiânia para divulgarem seus trabalhos.

Brasília continua sendo um pólo de criatividade e exportador de talentos e certamente algumas bandas poderão representar bem este estilo, conseguindo até destaque internacional.

O rock está para Brasília assim como o axé está para a Bahia, definiu o vocalista do Capital Inicial, Dinho Ouro Preto em entrevista antes do show do Brasilian Music Festival. 


\section{A MÚSICA POPULAR BRASILEIRA}

A música popular brasileira está presente em todo lugar e em toda gente: da cozinha ao sarau, do branquinho ao mulatinho.

Segundo Vasconcelos (1991, pág.14):

O relógio da música popular brasileira dispara, teoricamente, numa terça-feira, dia 21 de Abril de 1500. Mas se isso será verdade para duas das três grandes contribuições iniciais - a do português e a do negro - não se pode esquecer que $o$ Brasil já possuía a sua própria música que era, naturalmente, a dos seus aborígines.

Mas um outro ponto de vista é apresentado por José Ramos Tinhorão em seu livro "Pequena História da Música Popular":

Nos primeiros duzentos anos da colonização portuguesa no Brasil, a existência de
música popular se tornava impossível desde logo, porque não existia povo: os
indígenas viviam em estado de nomadismo; os negros eram considerados 'coisas';
e os brancos e mestiços constituíam uma minoria sem expressão... (Tinhorão,
1986, pág. 07)

Esta afirmação está fundamentada em uma distinção em que o autor coloca entre música folclórica e música popular, ou seja: música folclórica: de autor desconhecido, transmitida oralmente de geração em geração; música popular: composta por autores conhecidos e divulgada por meios gráficos (partituras), ou através de gravações (disco, fitas, filmes).

Isto equivale dizer que a música popular, para Tinhorão (1986, pág.07), ...constitui uma criação contemporânea do aparecimento de cidades com um certo grau de diversificação social.

Neste sentido, a música popular brasileira começa a aparecer juntamente com os primeiros centros urbanos, por volta de 1730 no Brasil colonial do século XVIII, quando Salvador e Rio de Janeiro despontam como as cidades mais progressistas da Colônia. Até isso então, os únicos tipos de música ouvidos no Brasil seriam os cantos das danças rituais dos indígenas, os "batuques" dos negros africanos e as 
canções e danças dos europeus colonizadores, ou seja, a música folclórica das três raças que constituíam o País naquele período.

Hoje se afirma com unanimidade que a música popular brasileira se formou, como síntese da nossa expressão musical urbana, através do hibridismo e da interinfluência de sons indígenas, negros e portugueses. 


\section{CHORO - GÊNERO MUSICAL}

O que mais fascina e impressiona todos os estudiosos que se aproximam do Choro é o fato de que uma forma de música popular seja ao mesmo tempo sofisticada, comunicativa e extremamente resistente. No limiar do ano 2000, o choro continua vivo, renovando-se e, apesar de não estar presente na chamada grande mídia, atraindo novas gerações.(Cazes, Henrique, 1999)

Gênero criado a partir da mistura de elementos das danças de salão européias (como o schottisch, a valsa, o minueto e, especialmente, a polca) e da música popular portuguesa, com influências da música africana.

De início, era apenas uma maneira mais emotiva, chorosa, de interpretar uma melodia, cujos praticantes eram chamados de chorões.

Como gênero, o choro só tomou forma na primeira década do século $X X$, mas sua história começa em meados do século XIX, época em que as danças de salão passaram a ser importadas da Europa. A abolição do tráfico de escravos, em 1850, provocou o surgimento de uma classe média urbana (composta por pequenos comerciantes e funcionários públicos, geralmente de origem negra), segmento de público que mais se interessou por esse gênero de música.

Raul Pederneiras, caricaturista, jornalista e autor de revistas teatrais, publicou em 1922, no Rio de Janeiro sob a indicação de Verbetes para um dicionário de gíria a seguinte definição para a palavra choro: Choro - baile, musicata; concerto de flauta, violão e cavaquinho; Música improvisada. Cair no choro, dançar.

A definição é interessante por mostrar que ao iniciar-se a década de $X X$, considerava o choro como uma forma de tocar e não como um gênero musical como é considerado hoje. Desde a metade do século XIX, o que se chama de choro era realmente a música tocada em bailes tendo como formação do conjunto executante os instrumentos: flauta, responsável pela condução da melodia principal; o cavaquinho, o centrador de ritmo; e violão harmonizador. 
A origem do termo choro já foi explicada de várias maneiras. Há alguns folcloristas que dizem que esse nome vem de xolo, um tipo de baile que reunia os escravos das fazendas. De xoro, o termo teria finalmente chegado a choro.

Vasconcelos (1991, pág. 19) sugere: o termo choro liga-se à corporação musical dos choromeleiros, muito atuantes no período colonial.

Tinhorão (1986, pág.103) defende outro ponto de vista: a origem do termo choro por meio da sensação de melancolia transmitida pelas baixarias do violão (o acompanhamento na região mais grave desse instrumento).

Já o músico Cazes (1999, pág.17), defende a tese de que: o termo decorreu desse jeito marcadamente sentimental de abrasileirar as danças européias.

Vários músicos e compositores contribuíram para que esse maneirismo inicial se transformasse em gênero. Autor da polca Flor Amorosa, que é tocada até hoje pelos chorões, Joaquim Antonio da Silva Callado foi professor de flauta do Conservatório de Música do Rio de Janeiro. De seu grupo fazia parte a pioneira maestrina Chiquinha Gonzaga, não só a primeira chorona, mas também a primeira pianista do gênero. Em 1897, Chiquinha escreveu para uma opereta o cateretê Corta-Jaca, uma das maiores contribuições ao repertório do choro. Outro pioneiro foi o clarinetista e compositor carioca Anacleto de Medeiros, que realizou as primeiras gravações do gênero, em 1902, à frente da Banda do Corpo de Bombeiros. Assim como outros registros posteriores, essas gravações indicam que a improvisação ainda não fazia parte da bagagem musical dos chorões naquela época.

Essencial para a formação da linguagem do gênero foi a obra de Ernesto Nazareth, que desde cedo extrapolou as fronteiras entre a música popular e a erudita. O autor de clássicos como Brejeiro, Odeon e Apanhei-te Cavaquinho destacou-se como criador de tangos brasileiros e valsas, mas de fato exercitou todos os gêneros musicais mais comuns daquela época. A sofisticação da obra de Nazareth era tamanha, que (exceto no caso de Radamés Gnattali, um de seus melhores intérpretes) sua obra só foi definitivamente integrada ao repertório básico 
dos chorões nos anos 40 e 50, por meio das gravações de Jacob do Bandolim e Garoto.

Também genial, Alfredo da Rocha Vianna Filho, o Pixinguinha, contribuiu diretamente para que o choro encontrasse uma forma definida. Para isso, introduziu elementos da música afro-brasileira e da música rural nas polcas, valsas, tangos e schottische dos chorões. É o caso do maxixe Os Oito Batutas, gravado em 1918, cujo título antecipou o nome do primeiro conjunto a conquistar fama na história da música brasileira. Protagonistas de uma polêmica temporada de seis meses em Paris, no ano de 1922, Pixinguinha e seus parceiros na banda Os Batutas (um septeto, na verdade) dividiram a imprensa e o meio musical brasileiro, entre demonstrações de ufanismo e desqualificação. Foi também sob duras críticas que Lamentos (de 1928) e Carinhoso (composto em 1917 e só gravado pela primeira vez em 28), dois inovadores choros de Pixinguinha, foram recebidos pela crítica. O fato de ambos terem sido feitos em duas partes, em vez de três, foi interpretado pelo preconceituoso crítico Cruz Cordeiro como uma inaceitável influência do jazz.

Outra personalidade de peso na história do gênero foi o carioca Jacob Pick Bittencourt, o Jacob do Bandolim, famoso não só por seu virtuosismo como instrumentista, mas também pelas rodas de choro que promovia em sua casa, nos anos 50 e 60. Sem falar na importância de choros de sua autoria, como Remeleixo, Noites Cariocas e Doce de Coco, que fazem parte do repertório clássico do gênero. Contemporâneo de Jacob, Waldir Azevedo superou-o em termos de sucesso comercial, graças a seu pioneiro cavaquinho e choros de apelo bem popular que veio a compor, como Brasileirinho (lançado em 1949) e Pedacinhos do Céu.

Um dos exemplos mais bem resolvidos de união entre o choro e o jazz pode ser encontrado na obra do maestro e arranjador pernambucano Severino Araújo, que pouco depois de se mudar para o Rio de Janeiro, em 1944, decidiu adaptar sambas e choros à linguagem das big bands. À frente da Orquestra Tabajara, Araújo gravou vários choros de sua autoria, como Espinha de Bacalhau e Um Chorinho em Aldeia, exemplos seguidos por outras orquestras do gênero ou compositores como Porfírio da Costa e K-Ximbinho. Outro brilhante adepto da fusão do choro com o jazz foi o 
maestro Radamés Gnattali, ao lado de quem atuaram talentosos músicos do gênero, como os violonistas Bola Sete, Laurindo de Almeida e Garoto. Mas foi com dois saxofonistas que Gnattali aprofundou mais suas experiências de aproximação com o jazz: Zé Bodega e Paulo Moura, músico que desde os anos 70 dedica parte de seu repertório ao choro.

O Rio de Janeiro é a incontestável capital do choro, mas não faltaram músicos de expressão no gênero, originários de outras partes do país. Um dos pioneiros foi o violonista João Pernambuco, que trocou o sertão pernambucano pelo Rio, em 1904. Além de ter feito parte do conjunto Os Oito Batutas, ele é até hoje cultuado pelos violonistas brasileiros, que continuam interpretando suas composições para violão. Incentivado pelos Batutas, o paraibano Severino de Carvalho, o Ratinho, também migrou para o Rio, em 1922. Um dos pioneiros na utilização do sax soprano, além de compositor de clássicos do gênero, como Saxofone, Por Que Choras?, ficou mais conhecido, porém, ao formar a famosa dupla caipira Jararaca e Ratinho. Outro solista nordestino de destaque, nos anos 20 e 30, foi o clarinetista e saxofonista sergipano Luís Americano, que integrou o inovador Trio Carioca, ao lado do pianista e maestro Radamés Gnattali, em 1937. Já o bandolinista pernambucano Luperce Miranda, que também tocava cavaquinho, radicou-se no Rio de Janeiro, em 1928, depois de tocar com os Turunas da Mauricéia. Notável também é o violonista e compositor Francisco Soares de Araújo, o Canhoto da Paraíba, que surpreende ao tocar seu instrumento sem inverter a posição das cordas, apesar de ser canhoto.

Outro centro de cultivo e desenvolvimento do gênero foi São Paulo, onde se destacaram chorões como os violonistas Armandinho Neves, Antônio Rago e, especialmente, Aníbal Augusto Sardinha, o Garoto. Virtuose do violão, ele acompanhou a cantora Carmen Miranda nos EUA, em 1939. O contato direto com o jazz influenciou sua obra, inclusive seus choros, que hoje são tocados por violonistas de vários cantos do mundo, incluindo o também paulista Paulo Bellinati, um dos principais divulgadores da obra de Garoto. Embora o choro continue sendo mais cultuado no Rio, é em São Paulo que têm acontecido os mais significativos eventos 
dedicados ao gênero, como os festivais promovidos pela TV Bandeirantes, nos anos 70, ou a recente série Chorando Alto, no Sesc Pompéia.

O choro conheceu um período de revitalização, nos anos 70, estimulado pelo show Sarau, com Paulinho da Viola e o grupo Época de Ouro (e em parte pelo sucesso do grupo Novos Baianos). Não apenas surgiram grupos jovens dedicados ao gênero, como os cariocas A Fina Flor do Samba, Galo Preto e Os Carioquinhas, mas um novo público se formou, ampliado por clubes de choro criados em cidades como Brasília, Recife, Porto Alegre, Belo Horizonte, Goiânia e São Paulo, entre outras. O novo interesse pelo gênero propiciou também a redescoberta de veteranos chorões, como Altamiro Carrilho, Copinha e Abel Ferreira, além de revelar talentos mais jovens, como os bandolinistas Joel Nascimento e Déo Rian. Sem dúvida, o músico mais brilhante dessa nova geração foi o violonista carioca Rafael Rabello, que apesar de ter morrido prematuramente, aos 32 anos, em 1995, deixou gravada uma obra de peso.

Já a partir dos anos 80, o choro passa a estabelecer outras conexões musicais. Grupos de espírito chorão, como a Camerata Carioca e a Orquestra de Cordas Brasileiras, também traziam em seus repertórios música erudita de Bach, Vivaldi e Villa-Lobos, ou mesmo o tango contemporâneo de Astor Piazzolla. Por outro lado, a música popular brasileira passou a flertar mais com o choro através de obras de influentes compositores e letristas, como Paulinho da Viola e Chico Buarque, ou instrumentistas, como Hermeto Pascoal. Já na última década, o choro vem recebendo uma ênfase especial na parceria do violonista e compositor Guinga com o veterano letrista Aldir Blanc, que elevaram o patamar das experiências com o choro vocal. Entre os músicos da atualidade que dedicam considerável parte de seu repertório ao choro chamam atenção o pianista Leandro Braga, o gaitista Rildo Hora, o clarinetista e saxofonista Nailor Proveta Azevedo e os flautistas Antônio Carlos Carrasqueira e Dirceu Leitte. 


\subsection{O Choro Atualmente}

Um fenômeno muito recente no Choro é o surgimento de trabalhos feitos por músicos estrangeiros a partir da musicalidade chorística. Quando a Camerata Carioca esteve no Japão, em 1985, foi surpreendida pela existência de músicos que tocavam e estudavam música brasileira.

Formada pelo bandolinista Oh Akioka, pelo violonista Shigeraru Sasago e pelo contrabaixista Jyoji Sawada, o Choro Club faz uma fusão da linguagem chorística com as tendências contemplativas da música oriental, resultando daí uma espécie de do Choro "zen". Com um repertório que mistura clássicos de Nazareth e Jacob e composições próprias, o Choro Club se firmou e hoje, já com meia dúzia de CDs lançados, ajuda concretamente a difundir o sotaque chorístico no Japão.

Dos Estados Unidos, vem o trabalho do bandolinista Mike Marshall, membro do Modern Mandolin Quartet. Após experimentar o estilo com o quarteto, que gravou Assanhado, de Jacob do Bandolim, Marshall realizou, com a ajuda do pianista brasileiro Jovino Santos Neto e de outros músicos norte-americanos, o CD Brasil (duets), no qual desenvolve uma maneira de tocar Choro com sotaque americano que ele apelidou de brasilian bebop.

Outro americano, o pianista David Chesky, lançou recentemente um disco em duo com violonista brasileiro Romero Lumambo de nome Chorinhos de Nova York, no qual cada faixa e associada a um ponto turístico de Manhattan.

Na Venezuela, país que tem grande tradição de bandolim, lá chamado de mandolina, o notável grupo Ensemble Gurufio inclui em seu repertório peças de Pixinguinha e Jacob do Bandolim, enquanto seu bandolinista, Cristóbal Sotto, tem percorrido o mundo executando a Suíte Retratos e o repertório de Jacob.

Mas é na Alemanha, que vamos encontrar a combinação mais improvável: um violonista egípcio, Ahmed El-Salamouny, tem como ponto principal de seu trabalho os choros de João Pernambuco e Dilermando Reis. Tocando com músicos 
brasileiros, Ahmed tem percorrido a Europa mostrando o violão popular do Brasil desde os pioneiros até contemporâneos como Marco Pereira e Paulo Bellinati.

Todas essas histórias apontam para uma crescente descoberta do Choro que, se por enquanto não produziu nenhum trabalho genial, tem servido para abrir caminho para que essa música seja conhecida nos quatro cantos do mundo

\subsection{O Choro em Brasília}

Na década de 60 quando é inaugurado a nova capital, vários músicos vieram para Brasília com a finalidade de trabalhar nos conjuntos da Rádio Nacional. Outros, profissionalizados e não-profissionalizados mudaram para a capital em busca de uma nova perspectiva de vida. Alguns deles eram músicos de choro, ou simplesmente "Chorões", e passaram a produzir este estilo musical na cidade, dando início ao desenvolvimento das atividades musicais envolvendo o gênero. Dentre eles, Pernambuco do Pandeiro, João Tomé, Chico Gil, Avena de Castro e outros. Alguns músicos passaram a reunir-se informalmente em casas de família para executar alguns de continuidade ao processo de desenvolvimento do choro na cidade, agora com a composição de músicas.

Uma destas casas onde eram feitas as reuniões de músicos era a residência da professora Odeth Ernest Dias, onde freqüentavam, entre outros, Celso do clarinete, Pernambuco do Pandeiro, Avena de Castro. A partir daí surgiu a necessidade de oficialização daqueles encontros; por este motivo, foi criado o primeiro estatuto do Clube do Choro de Brasília, que ganhou sua sede oficial em 1977. Seu primeiro presidente foi Avena de Castro. Depois dele, outros passaram pela presidência do clube: Lício da flauta, Six, Américo e atualmente Reco do Bandolim. O Choro de Brasília encontra-se em um contínuo processo de 
desenvolvimento e amadurecimento. A cidade já é considerada nacionalmente como um grande pólo de produção de Choro. 


\section{A TRAJETÓRIA DO CLUBE DO CHORO DE BRASÍLIA}

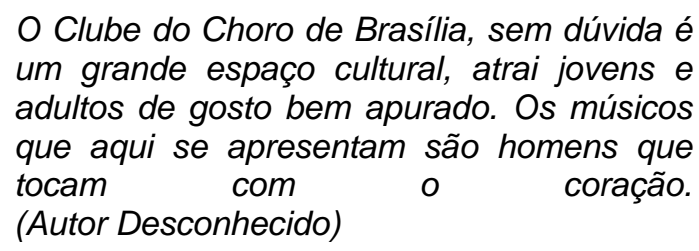

O choro chegou à Brasília com sua inauguração, levado pelos funcionários públicos transferidos para a nova capital. Quarenta anos depois, a cidade é sede não só do Clube do Choro mais ativo e importante do País, como também da Escola de Choro "Raphael Rabello", a primeira do gênero no Brasil, de onde saem fornadas de jovens músicos dispostos a levar adiante a bandeira erguida por Pixinguinha, Ernesto Nazareth, Chiquinha Gonzaga, Jacob do Bandolim e Waldyr Azevedo.

\subsection{A Sede}

Nas palavras do jornalista, crítico e historiador Sérgio Cabral, o Clube do Choro de Brasília é hoje uma das instituições culturais mais importantes do País. Situado no coração do Eixo Monumental da cidade, ao lado do Centro de Convenções "Ulysses Guimarães", a sede do Clube tem o formato de um caféconcerto, com moderno equipamento de som e vídeo, sistema de ar condicionado, palco de 15 metros quadrados e acomodações para 300 pessoas.

Em 2002 o Clube do Choro de Brasília comemorou vinte e cinco anos com o projeto "Caindo no Choro", que trouxe à cidade 88 artistas de diferentes tendências musicais, vindos de nove estados, além de 37 atrações locais. O sucesso da iniciativa pôde ser comprovado pelo público recorde de 30 mil pessoas que 
compareceu à casa no decorrer do ano, comprovando o vigor e a perenidade do Choro.

Com a aprovação pelo Ministério da Cultura do projeto "Tributo a Garoto", que em 2003 revisita a obra do grande violonista brasileiro Aníbal Augusto Sardinha, sob o indispensável patrocínio do Banco do Brasil, Correios e Petrobrás, o Clube do Choro de Brasília reafirma a condição de promotor do mais duradouro e bem sucedido evento de Música Popular Brasileira instrumental realizado no País.

São sete anos consecutivos de projetos homenageando ícones da nossa música popular, como Pixinguinha, Jacob do Bandolim, Waldyr Azevedo, Chiquinha Gonzaga e Ernesto Nazareth. Nesse período, o Clube foi palco de 705 shows, protagonizados por 391 artistas convidados e 431 atrações locais, e assistidos por um público estimado em 120 mil pessoas.

Segundo o presidente do Clube do Choro de Brasília, Reco do Bandolim (2002):

... Grande parte desse público é de jovens que nunca tiveram acesso à Música Popular Brasileira mais genuína, vetada pela mídia comercial. Mas foram atraídos pelo trabalho realizado não apenas pelo Clube, mas também pela Escola de Choro Raphael Rabello, a primeira do gênero no Brasil."

\subsection{A Fundação}

A transferência da Capital do Rio de Janeiro para Brasília trouxe para o Distrito Federal uma grande leva de funcionários públicos, entre os quais se incluíam alguns chorões ilustres. O citarista Avena de Castro, o flautista Bide, o percussionista Pernambuco do Pandeiro, o saxofonista Nilo Costa, o trombonista Tio João e o violonista Hamilton Costa, entre outros, se juntaram aqui à pianista Neuza França, a flautista Odete Ernest Dias, ao percussionista Valci e ao cavaquinista Francisco Assis Carvalho. 
Inicialmente, as reuniões aconteciam nas casas dos chorões. Na década de 70, vieram as primeiras apresentações em espaços públicos, com grande sucesso. Um desses shows foi assistido pelo então governador Elmo Serejo Farias, que, empolgado com o que viu e ouviu, cedeu as instalações de um antigo vestiário do Centro de Convenções para as reuniões dos músicos. A partir daí veio a decisão de fundar o Clube do Choro de Brasília, concretizada no dia 09 de setembro de 1977.

Depois de um início promissor, com a incorporação de jovens músicos da cidade e anos de intensa atividade, o Clube conheceu a decadência. A precariedade das instalações do antigo vestiário, os repetidos furtos do equipamento de som, o rompimento do sistema de esgotos e a falta de uma estrutura mínima para a apresentação dos músicos e o conforto da platéia acabaram por afastar o público e os próprios chorões. O local ficou abandonado e o Clube do Choro de Brasília chegou a ser ameaçado de despejo. Por fim, tornou-se abrigo de mendigos e desocupados.

\subsection{A Reforma}

Em 1993 foi eleita a diretoria, presidida pelo jornalista Henrique Lima Santos Filho, o Reco do Bandolim. Depois de interromper o processo de despejo no Governo do Distrito Federal, ela conseguiu em 1995 a regularização da sede junto à Terracap. E partiu para a recuperação do espaço físico, através de um projeto do arquiteto Fernando Andrade, autorizado pelo próprio Oscar Niemeyer e executado pela NOVACAP. Artistas de renome nacional, como o violonista Raphael Rabello e o bandolinista Armando Macedo, fizeram shows na sala Villa Lobos sem cobrar cachê, com a renda revertida para as obras de recuperação do Clube.

Com a conclusão da reforma, em 1997, a Diretoria do Clube do Choro de Brasília passou a dedicar-se ao trabalho de reaglutinação dos músicos e aficcionados do gênero. Ao mesmo tempo, apresentou ao Ministério da Cultura um projeto anual temático, homenageando o centenário de nascimento de Pixinguinha. 
A proposta obteve o beneficio da Lei do Mecenato, permitindo a adesão de patrocinadores como o Banco do Brasil, a ECT e a Petrobrás, que viabilizaram a contratação de músicos da cidade e de outros centros para apresentações semanais. Uma pequena estrutura de produção foi montada, tendo em vista a divulgação do projeto e a recuperação da credibilidade junto ao público, que estivera afastado por longo tempo. A sede passou a abrigar exposições permanentes sobre os músicos homenageados, além de discoteca e videoteca de música instrumental brasileira.

A partir daí, o Clube do Choro de Brasília trilhou um caminho de sucesso. Com shows veiculados para todo o País através das TVs Senado, Câmara e TVE, que alcançam um público estimado em 12 milhões de telespectadores. O Clube forma uma parceria estratégica com a Escola de Choro Raphael Rabello, patrocinada pela TCO Celular, hoje com cerca de 200 alunos.

Reco do Bandolim, presidente do Clube do Choro de Brasília afirma:

A Escola revela talentos. O Clube é o lugar onde eles entram em contato com o público, ao lado de grandes nomes e chorões tradicionais, cumprindo o papel de formar e ampliar platéias. E aí está criado o círculo virtuoso que vai garantir a renovação e a perenidade do Choro.

No dia 20 de dezembro de 2002, o Clube do Choro de Brasília concluiu o projeto "Caindo no Choro", tendo cumprido rigorosamente todos os itens propostos ao Ministério da Cultura, a exemplo do que vem ocorrendo nos últimos sete anos. Aliás, é esse o requisito básico exigido pelo Ministério da Cultura para a aprovação de novos projetos. Para satisfação da diretoria do Clube, o projeto "Tributo a Garoto", com execução em 2003, foi aprovado com destaque pela Comissão Nacional de Incentivo à Cultura - CNIC, por ter sido considerado uma proposta de relevância para a cultura brasileira. 


\subsection{O Clube do Choro e o turismo de Brasília}

Brasília por ser a capital da República e cidade planejada atrai um número bastante expressivo de turistas. Isto se deve também pelo fato da cidade ser o centro das decisões e do poder, com uma arquitetura arrojada conhecida mundialmente e também por ser uma cidade multicultural. Sua população reúne traços de todas as regiões do país, somando à cultura de outros povos através das representações diplomáticas e de organismos internacionais.

A cidade apresenta excelente infraestrutura hoteleira e de serviços, mão de obra qualificada, dispondo de muitas opções para se hospedar e se divertir. Bares e restaurantes sofisticados, casas de shows, centros de convenções, shoppings, entre outras opções de lazer e entretenimento.

O turismo cultural, onde a música se consagra sendo uma característica da capital (cidade do rock, hip hop, forró, axé, reggae) explora as diferentes regiões do Brasil bem como de outros países, motivando ainda mais o turista que visita Brasília. O Clube do Choro de Brasília, espaço cultural e mais do que nunca um atrativo turístico se destaca com merecida excelência. A direção do Clube tem apresentado um trabalho sério de qualidade e desenvolvendo um papel social importante.

O Clube do Choro de Brasília tem muito contribuído para o desenvolvimento do turismo e da cultura em Brasília, atraindo um público de qualidade, gerando empregos diretos e indiretos para a população, e sem dúvida, colaborando positivamente para a divulgação da capital como atrativo cultural e turístico brasileiro. 


\section{CONSIDERAÇÕES FINAIS}

Brasília hoje representa um dos mais importantes pólos turísticos emergentes do Brasil, e um grande mercado para implantação de empreendimentos no setor

O turismo de negócios e de eventos juntamente com o turismo cultural e cívico cresce a cada dia, movimentando significadamente sua economia. A capital é bastante requisitada para a realização de encontros políticos, congressos, seminários, fóruns, etc. A qualidade dos serviços e a infra-estrutura dos espaços para eventos e dos hotéis contribui para o crescimento da atividade.

O Clube de Choro de Brasília é antes de tudo um espaço cultural, um lugar de música e serviço de qualidade, sendo também mais um atrativo turístico da cidade de Brasília, uma opção cultural a mais para o turista. O número de novos visitantes cresce a cada apresentação artística, modificando o perfil dos freqüentadores que até então eram de pessoas adultas. Observa-se hoje um grande interesse por jovens. Os freqüentadores cativos, permanecem fies, colaborando e divulgando o Clube. Há uma harmonia e sintonia muito forte por parte destes, sendo verdadeiros admiradores deste espaço de lazer e entretenimento.

A divulgação local das apresentações do Clube do Choro de Brasília é bastante significativa, jornais, rádio, televisão, revistas especializadas de entretenimento e de música, internet e talvez o mais importante, o boca-a-boca de quem já é freqüentador assíduo do Clube.

Por mais que alguns freqüentadores não reconheçam, o Clube de Choro de Brasília é um atrativo turístico. E sem dúvida já faz parte da identidade cultural da capital. 
ANEXOS 
Anexo I - Material publicitário confeccionado pelo Clube do Choro de Brasília para a divulgação dos eventos dos meses de novembro e dezembro de 2003. 


\section{Anexo II - Questionário aplicado no Clube do Choro de Brasília, na apresentação do pianista Maestro Laércio de Freitas, dia 28 de novembro de 2003.}

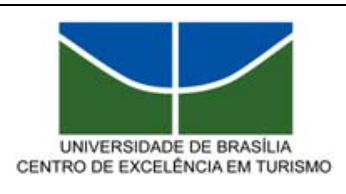

Brasília-DF, novembro de 2003.

Prezado Senhor(a),

Solicito a sua cooperação no sentido de responder este questionário, pois os dados aqui obtidos servirão de base para um trabalho de monografia do Curso de Especialização para Professores e Pesquisadores em Turismo e Hospitalidade, ministrado pelo Centro de Excelência em Turismo da Universidade de Brasília, o qual pretende analisar, basicamente o perfil dos freqüentadores do Clube do Choro de Brasília.

\section{1) Sexo:}

_feminino masculino

\section{2) Faixa etária:}

menor de 18 anos de 18 a 30anos de 31 a 49anos acima de 50anos

3) Grau de escolaridade:

_ superior __superior incompleto

$2^{\circ} \mathrm{grau}$ $1^{\circ} \mathrm{grau}$

4) É residente em Brasília?

_ $\operatorname{sim}$ _ não Se não, em qual cidade reside?

5) Primeira vez que visita o Clube do Choro de Brasília?

sim não

6) Como ficou conhecendo o Clube do Choro de Brasília?

_ornais _ internet__evistas _amigos outros

7) Conhece em outra cidade um espaço cultural como este? sim —não Onde? 
Galeria dos presidentes do Clube do Choro de Brasília.

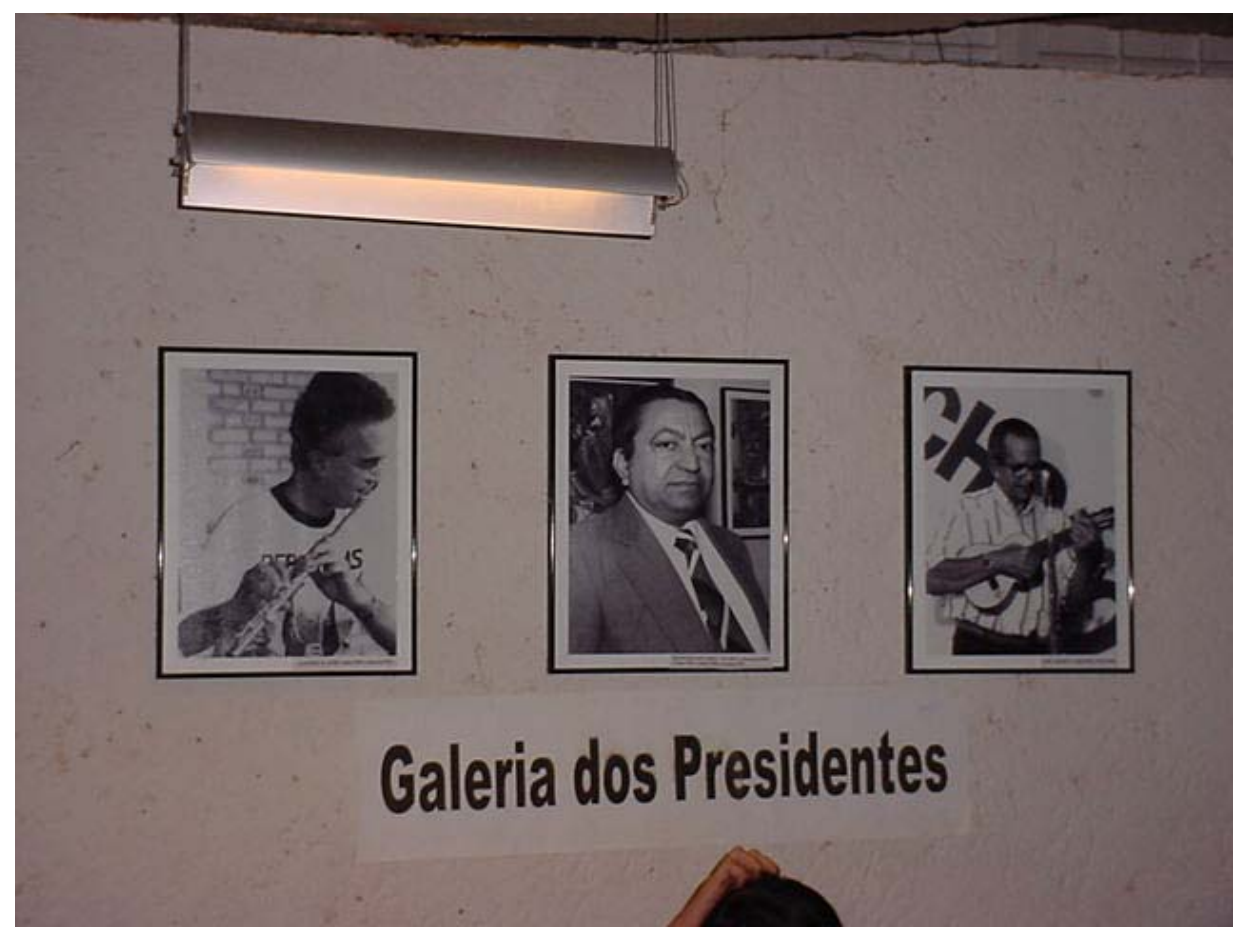

Fonte: Jusnei de Almeida Silva/novembro de 2003.

Alfredo da Rocha Vianna Filho "Pixinguinha" (quadro) e seu primo.

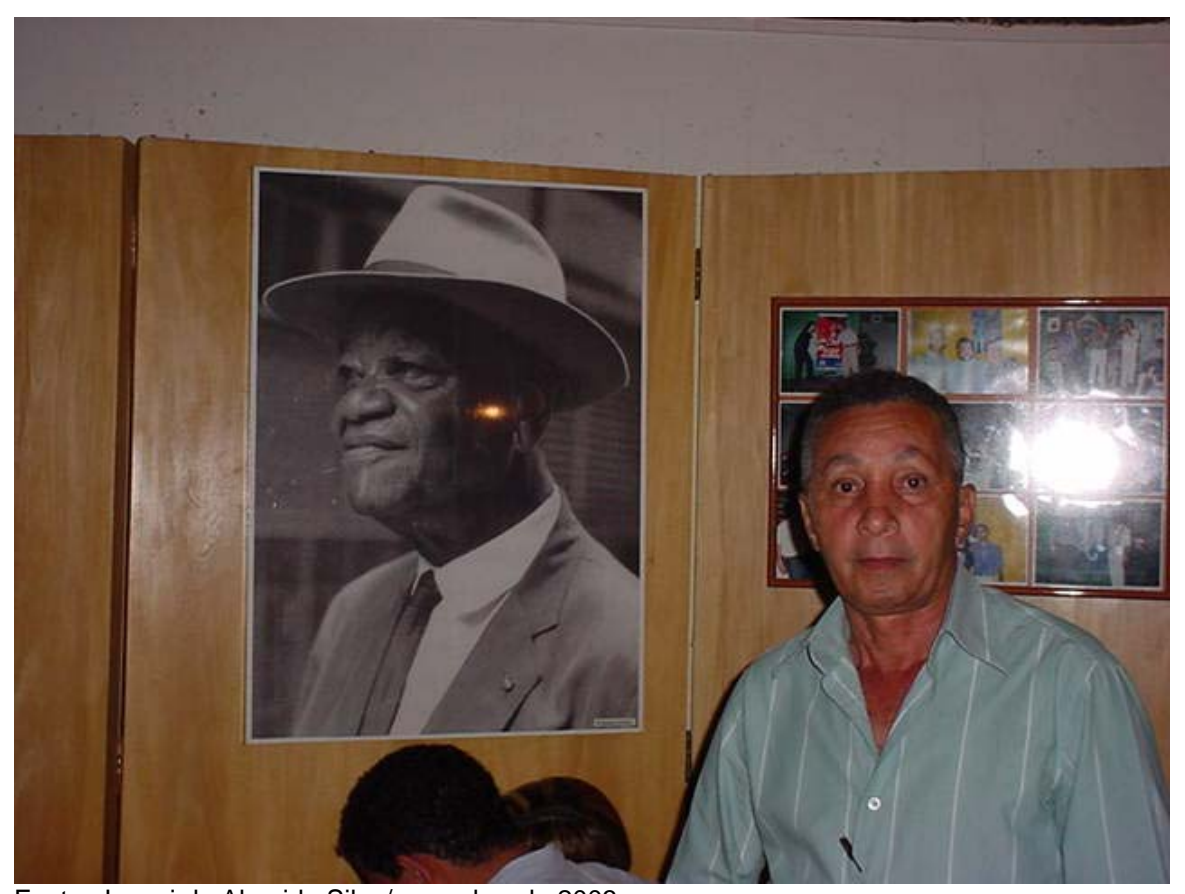

Fonte: Jusnei de Almeida Silva/novembro de 2003. 


\section{Chiquinha Gonzaga.}

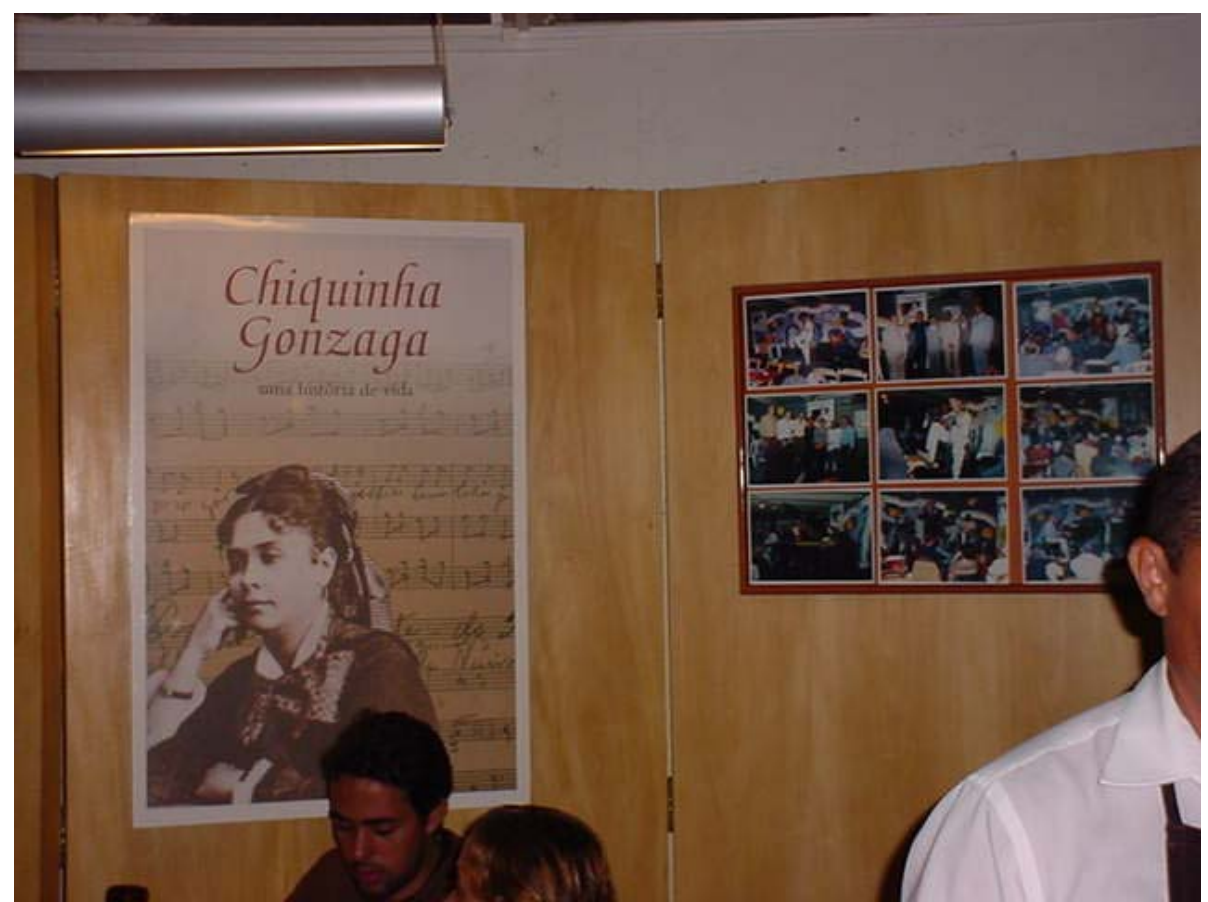

Fonte: Jusnei de Almeida Silva/novembro de 2003.

\section{Aníbal Augusto Sardinha "Garoto".}

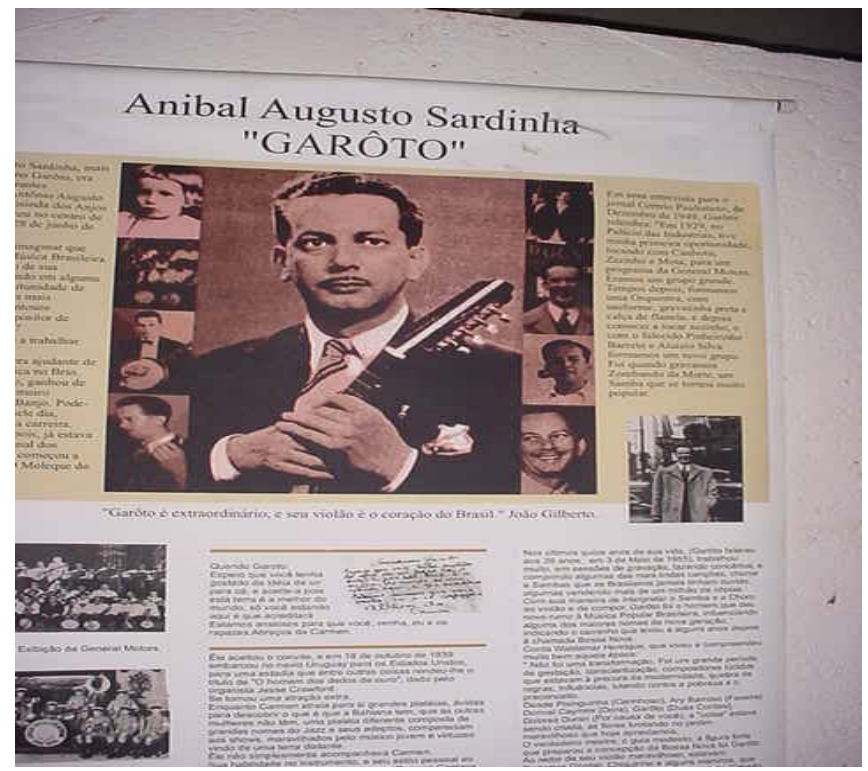

Fonte: Jusnei de Almeida Silva/novembro de 2003. 
Waldyr Azevedo.

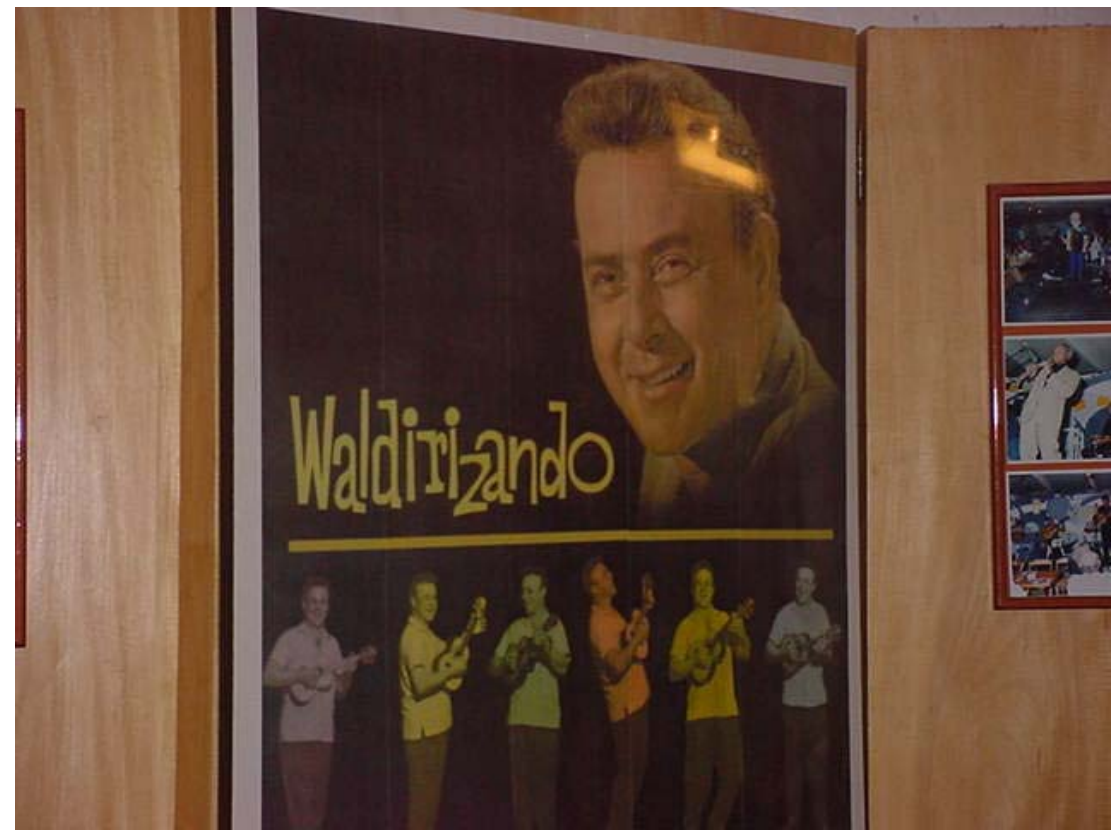

Fonte: Jusnei de Almeida Silva/novembro de 2003.

Piano usado nas apresentações do Clube do Choro de Brasília.

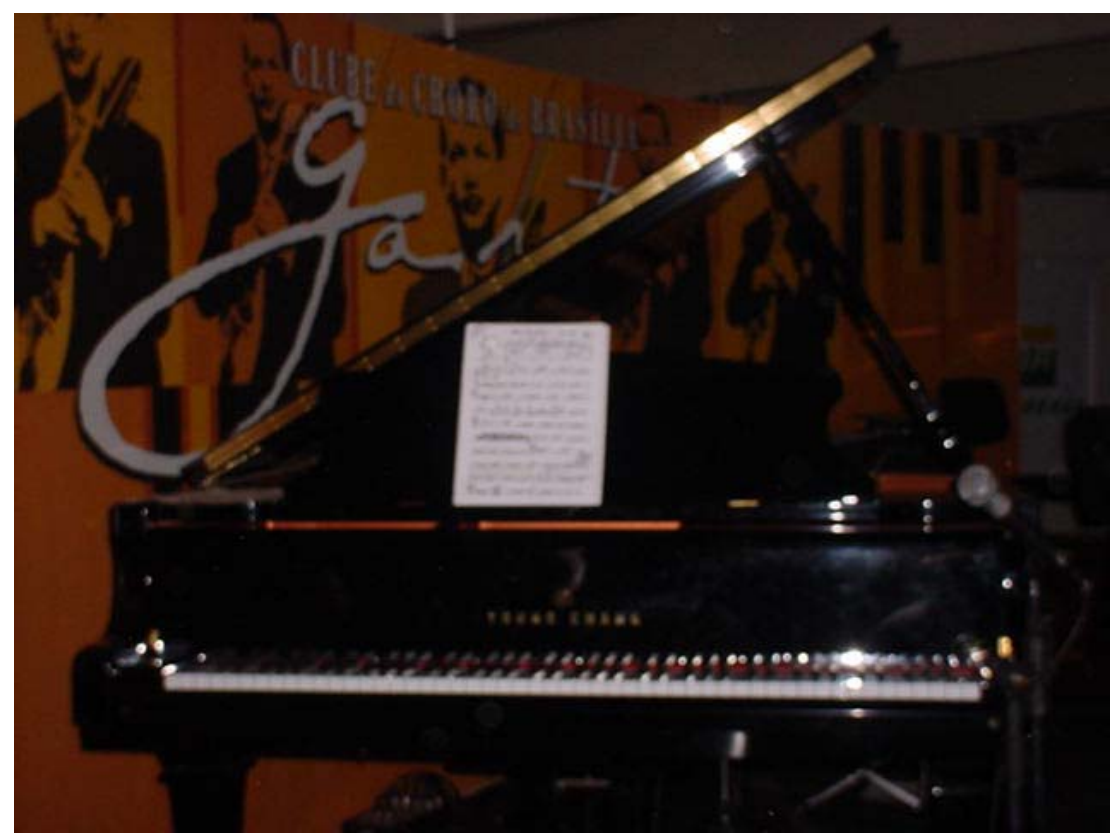

Fonte: Jusnei de Almeida Silva/novembro de 2003. 
Visitantes do Clube do Choro de Brasília: apresentação do Maestro Laércio em 28 de novembro de 2003.

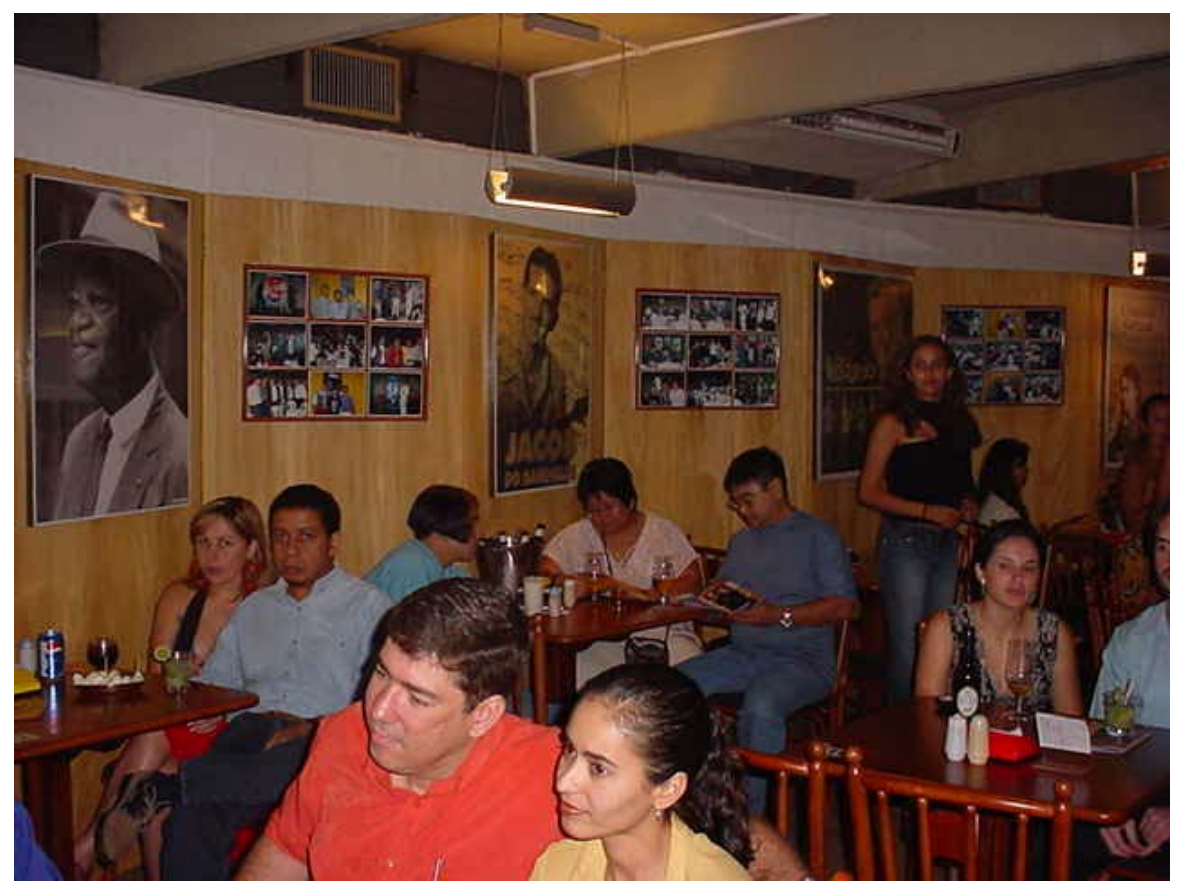

Fonte: Jusnei de Almeida Silva/novembro de 2003.

Maestro Laércio de Freitas (pianista).

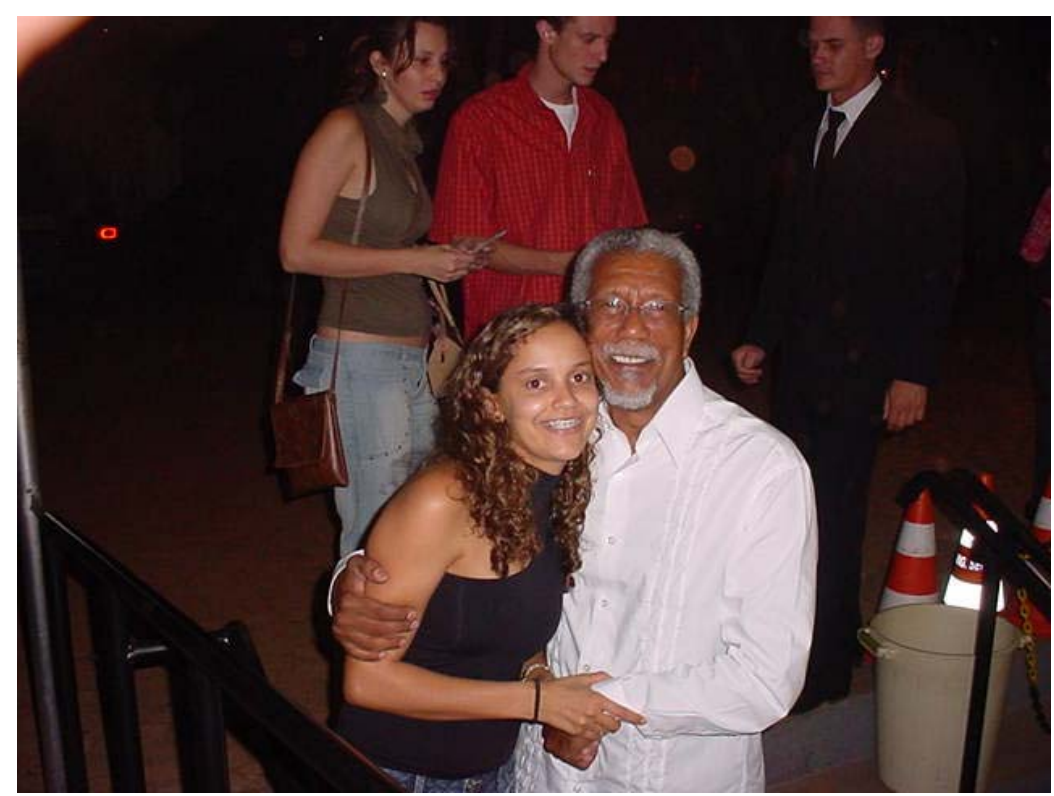

Fonte: Jusnei de Almeida Silva/novembro de 2003. 


\section{REFERENCIAS BIBLIOGRÁFICAS}

BARRETO, Margarida. Manual de iniciação ao estudo do turismo. 2. ed. Campinas: Papirus, 1997.

Turismo e legado cultural. 3.ed. Campinas: Papirus, 2002.

CAZES, Henrique. Choro: do quintal ao municipal. 2. ed. São Paulo: 34, 1999.

FARIA, Gabriela Barbosa de. Brasília: Patrimônio da humanidade e o turismo. 2002. 48 f. Monografia (Especialização em Gestão e Marketing do Turismo) - Centro de Excelência em Turismo, Universidade de Brasília, Brasília.

FONTOURA, Elaine Justino. Turismo cultural: estudo de caso da Laurex Eventos e Turismo Ltda. 2002. 54 f. Monografia (Especialização Gestão de Marketing de Turismo) - Escola de Turismo e Hotelaria Barreira Roxa, Centro de Excelência em Turismo, Universidade de Brasília, Brasília.

FRANÇA, Junia Lessa. et al. Manual para normalização de publicação técnicocientíficas. 5. ed. Belo Horizonte: UFMG, 2001.

FRANÇA, Olga Eurípedes. Arte e turismo: o turismo na rota das artes visuais em Brasília. 2000. 52 f. Monografia (Especialização em Gestão e Marketing do Turismo) - Centro de Excelência em Turismo, Universidade de Brasília, Brasília.

FREITAS FILHO, Luiz Rufino. Análise do perfil do turista do Distrito Federal. 2002. 43 f. Monografia (Especialização em Gestão e Marketing do Turismo II) - Centro de Excelência em turismo, Universidade de Brasília, Brasília. 
GUSMÃO, João Bernardo. A capital e seus imaginários: o turismo em Brasília. 2000. 60 f. Monografia (Especialização em Gestão e Marketing do Turismo) - Centro de Excelência em Turismo, Universidade de Brasília, Brasília.

KUBITSCHEK, Jucelino. Por que construí Brasília. Rio de Janeiro: Bloch, 1975.

MELGAR, Ernesto. Fundamentos de planejamento e marketing em turismo. São Paulo: Contexto, 2001.

MIOTTO, Janaína Vanella de Castro. Perfil das pessoas que viajam para Brasília. 2000. 68 f. Monografia (Especialização em Gestão em Marketing e Turismo) - Centro de Excelência em Turismo, Universidade de Brasília, Brasília.

PELLEGRINI FILHO, Américo. Ecologia, cultura e turismo. 7. ed. Campinas: Papirus, 1993.

PIRES, Mário Jorge. Lazer e turismo cultural. 2. ed. Barueri: Manole, 2002.

PORTELA, Patrícia de Oliveira. et al. Manual de Orientações para trabalhos técnicoscientíficos e referências bibliográficas. Uberaba: Universidade de Uberaba, 2001.

REJOWSKI, Mirian. Turismo e pesquisa científica. 2. ed. Campinas: Papirus, 1998.

RODRIGUES, Ady Balastreri. Turismo e espaço: rumo a um conhecimento transdisciplinar. São Paulo: Hucitec, 1997.

SALES, Fernando. MPB em pauta. Rio de Janeiro: Livraria José Olympio, 1984.

SWARBROOKE, Jonh. Turismo sustentável: turismo cultural, ecoturismo e ética. São Paulo: Aleph, 2000. ( volume 05) 
TINHORÃO, José Ramos. Pequena história da música popular brasileira: da modinha a lambada. 6. ed. São Paulo: Art, 1991.

VASCONCELLOS, Ary. Raízes da música popular brasileira. Rio de Janeiro: Rio Fundo, 1991.

VELLASCO, Ana Maria M. Manual de orientações para a produção de textos acadêmicos. Brasília: Universidade de Brasília, 2003.

Documentos consultados on line:

Disponível em: http://www.cidadeshistoricas.art.br/saoluis/sl_cul_p.htm

Disponível em: http://www.clubedochoro.com.br

Disponível em: http://www.quadranews.com.br/index.php?materia=755

Disponível em: http://www.persocom.com.br/chorodebrasilia

Disponível em: http://www.portaldorock.com.br/rockinrio/dia18.htm

Disponível em: http://www.unb.br 